\title{
(-)-Epigallocatechin-3-Gallate Inhibits CC Chemokine Ligand 11 Production in Human Gingival Fibroblasts
}

\author{
Yoshitaka Hosokawa ${ }^{a}$ Ikuko Hosokawa ${ }^{a}$ Satoru Shindo ${ }^{a}$ Kazumi Ozakib \\ Takashi Matsuo \\ Department of a Conservative Dentistry and Institute of Health Biosciences, The University of Tokushima \\ Graduate School, Tokushima, Tokushima, Japan; ${ }^{b}$ Department of Oral Health Care Promotion, School \\ of Oral Health and Welfare, Faculty of Dentistry, The University of Tokushima, Tokushima, Tokushima, \\ Japan
}

\section{Key Words}

Green tea catechin $•$ Human gingival fibroblast $•$ CCL11 $•$ MAPK

\begin{abstract}
Background: CC chemokine ligand 11 (CCL11) is related to Th2 cells migration via CC chemokine receptor 3 (CCR3). Th2 cells are involved in the etiology of periodontal disease. However, how the infiltration of Th2 cells is controlled in periodontally diseased tissues is unknown. (-)-Epigallocatechin gallate (EGCG), the major catechin in green tea, has multiple beneficial effects, but the effects of EGCG on CCL11 production are uncertain. In this study, we investigated whether cytokines could induce CCL11 production in human gingival fibroblasts (HGFs). Moreover, we examined the effects of EGCG on CCL11 production in HGFs. Methods and Results: ELISA analysis disclosed that interleukin (IL)-4 synergistically enhanced CCL11 production in IL-1 $\beta$ or tumor necrosis factor (TNF)- $\alpha$-stimulated HGFs. EGCG prevented IL-1 $\beta$ / IL-4 or TNF- $\alpha /$ IL-4-mediated CCL11 production in a concentration dependent manner. CCL11 production in HGFs was positively regulated by p38 mitogen-activated protein kinase (MAPK), extracellular signal-regulated kinase (ERK), and c-Jun $\mathrm{N}$ terminal kinase (JNK). Western blot analysis revealed that EGCG treatment prevented IL-1 $\beta / \mathrm{IL}-4$ or TNF- $\alpha / \mathrm{IL}-4$-induced ERK and JNK activation in HGFs. Conclusions: These data provide that CCL11 production in HGFs could be associated with Th2 cells infiltration in periodontal lesions. Moreover, EGCG is useful for periodontitis treatment to inhibit CCL11 production.
\end{abstract}




\section{Introduction}

Periodontal disease is a chronic inflammation of the tooth-supporting soft tissue and alveolar bone due to infection by microbes in dental plaque, which causes tooth loss if untreated. Host immune responses have been suggested to play a key role in periodontal diseases $[1,2]$. T and B lymphocytes appear to be prominent in chronic periodontal lesions in humans $[3,4]$. Th2 cells have been focused on the etiology of periodontal disease. Myneni and the colleagues reported that Tannerella forsythia, which is a periodontal pathogenic bacteria, -induced TLR2 activation resulted in alveolar bone destruction in a mouse periodontal disease model. Furthermore, Th2 development downstream of TLR2 activation was associated with alveolar bone destruction caused by Tannerella forsythia [5]. This report means that Th2 cells are positively involved in the pathogenesis of periodontal disease.

CC chemokine ligand 11 (CCL11) belongs to the CC chemokine family and have the potent chemotactic activity for CCR3 positive cells such as eosinophils, basophils, and Th2 cells [68]. CCL11 protein is increased in various inflammatory diseases that are characterized as Th2 type diseases, such as allergic asthma [9], allergic rhinitis [10], and atopic dermatitis [11], and is thought to be a key player in the etiology of these diseases. Reports about CCL11 expression in periodontal lesions are few. Thunell and the colleagues recently reported that a multiplex immunoassay disclosed that CCL11 protein was expressed in gingival crevicular fluid from periodontal lesion [12]. However, the source of CCL11 in gingival crevicular fluid is uncertain.

Green tea is one of the most popular beverages in the world and it has received considerable attention because of its beneficial effects on human health [13]. These effects have been largely attributed to the most epidemic polyphenol contained in green tea, (-)-epigallocatechin gallate (EGCG) [14]. We previously reported that EGCG have an antiinflammatory effect on human gingival fibroblasts (HGFs) [15-17]. We found that EGCG could prevent IL-6 production in tumor necrosis factor superfamily 14-stimulated HGFs [15]. However, the effect of EGCG on Th2-type chemokines, such as CCL11, production is uncertain in any types of cells as far as we know.

The aim of this study was to reveal the effect of IL-1 $\beta$ (a proinflammatory cytokine), TNF- $\alpha$ (a proinflammatory cytokine), and IL-4 (a Th2 cytokine) on CCL11 production in HGFs. Moreover, we examined the effects of EGCG on CCL11 production in IL-1 $\beta / \mathrm{IL}-4$ or TNF- $\alpha /$ IL-4-stimulated HGFs. Furthermore, we investigated whether EGCG treatment modified mitogen-activated protein kinases (MAPKs) in HGFs.

\section{Materials and Methods}

\section{Gingival tissue biopsies and cell culture}

We used HGFs that were isolated from three clinically healthy gingiva during routine distal wedge surgical procedures. The gingival specimens were cut into small pieces and transferred to culture dishes. The HGFs that grew from the gingiva were primarily cultured on $100 \mathrm{~mm} 2$ uncoated plastic dishes in Dulbecco's modified Eagle medium (DMEM-high glucose: Gibco, Grand Island, NY, USA) supplemented with

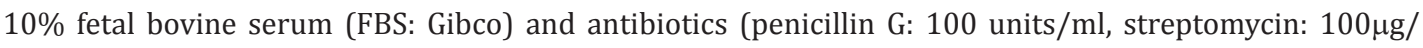
$\mathrm{ml}$ ) at $37{ }^{\circ} \mathrm{C}$ in humidified air with $5 \% \mathrm{CO}_{2}$. Confluent cells were transferred and cultured for use in the present study. After three to four subcultures with trypsinization, the cultures contained homogeneous, slim, and spindle-shaped cells growing in characteristic swirls. The cells were used for experiments after five passages. Informed consent was obtained from all subjects participating in this study. The study was performed with the approval and compliance of the University of Tokushima Ethical Committee (No. 329).

\section{CCL11 production in HGFs}

The HGFs were stimulated with IL-1 $\beta$ (Peprotech, Rocky Hill, NJ, USA), TNF- $\alpha$ (Peprotech), or IL-4 (Peprotech) for 24 hours. The supernatants from the HGFs were collected, and the CCL11 concentrations of the culture supernatants were measured in triplicate with ELISA. Duoset (R\&D systems, Minneapolis, 
MN, USA) was used for the determination. All assays were performed according to the manufacturer's instructions, and cytokine levels were determined using the standard curve prepared for each assay. In selected experiments, the HGFs were cultured for 1 hour in the presence or absence of EGCG $(3.125,6.25$, 12.5, 25, or $50 \mu \mathrm{g} / \mathrm{ml}$ : Sigma, St. Louis, MO, USA), SB203580 (20 $\mu \mathrm{M}$ : Santa Cruz Biotechnology, Santa

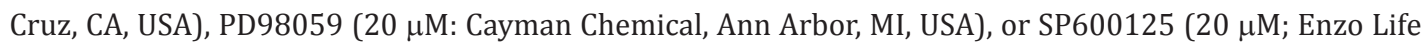
Sciences, Plymouth Meeting, PA, USA) prior to their incubation with IL-1 $\beta$, TNF- $\alpha$, or IL-4 stimulations. We prepared EGCG solution freshly in the each experiment.

\section{Western blot analysis}

To confirm the effects of EGCG on IL-1 $\beta+$ IL-4 or TNF- $\alpha+$ IL-4-induced phosphorylation of signal transduction molecules, Western blot analysis was performed. After EGCG $(25 \mu \mathrm{g} / \mathrm{ml})$ treatment for 1 hour, HGFs were stimulated with IL-1 $\beta(10 \mathrm{ng} / \mathrm{ml})+\mathrm{IL}-4(10 \mathrm{ng} / \mathrm{ml})$ or TNF- $\alpha(10 \mathrm{ng} / \mathrm{ml})+\mathrm{IL}-4(10 \mathrm{ng} / \mathrm{ml})$, and were washed once with cold PBS, before being incubated on ice for 5 min with Cell Lysis Buffer $(20 \mathrm{mM}$ Tris-HCl, $150 \mathrm{mM} \mathrm{NaCl}, 1 \mathrm{mM}$ Na2EDTA, $1 \mathrm{mM}$ EGTA, 1\% Triton, 2.5mM sodium pyrophosphate, $1 \mathrm{mM}$ $\beta$-glycerophosphate, $1 \mathrm{mM} \mathrm{Na} 3 \mathrm{VO} 4$, and $1 \mu \mathrm{g} / \mathrm{ml}$ leupeptin; Cell signaling technology, Danvers, MA, USA) supplemented with Protease Inhibitor Cocktail (104mM AEBSF, $0.085 \mathrm{mM}$ aprotinin, $4 \mathrm{mM}$, bestatin, 1.4 mM, E-64, 2 mM leupeptin, and $1.5 \mathrm{mM}$ pepstatin A; Sigma). After removal of debris by centrifugation, the protein concentrations of the lysates were quantified with the Bradford protein assay using IgG as a standard. A $20 \mu \mathrm{g}$ protein sample was loaded onto a 4-20\% SDS-PAGE gel, before being electrotransfered to a PVDF membrane. The activations of p38 MAPK, extracellular signal-regulated kinase (ERK) or c-Jun N terminal kinase (JNK) was assessed using phospho-p38 MAPK rabbit monoclonal antibody (Cell signaling technology), phospho-ERK rabbit monoclonal antibody (Cell signaling technology), phospho-JNK rabbit monoclonal antibody (Cell signaling technology), p38 MAPK rabbit monoclonal antibody (Cell signaling technology), ERK rabbit monoclonal antibody (Cell signaling technology), JNK rabbit monoclonal antibody (Cell signaling technology), or actin rabbit monoclonal antibody (Sigma) according to the manufacturer's instructions. Protein bands were visualized by incubation with the HRP-conjugated secondary antibody (Sigma), followed by detection using the ECL system (GE Healthcare, Uppsala, Sweden).

\section{Statistical analysis}

Experimental data were expressed as standard errors of the means and were analyzed using one-way ANOVA to compare the difference between EGCG or signal inhibitors treatment groups and the control groups. Statistical significance was defined as $\mathrm{p}<0.05$.

\section{Results}

Effects of IL-1 $\beta$, TNF- $\alpha$, or IL-4 stimulations on CCL11 production from HGFs

We first examined whether IL-1 $\beta$, TNF- $\alpha$, or IL-4 could induce CCL11 production in HGFs. Fig. $1 \mathrm{~A}$ shows that a single stimulation of IL-1 $\beta$ or IL- 4 significantly induced CCL11 production in HGFs. Moreover, IL-4 synergistically enhanced CCL11 production in IL$1 \beta$-stimulated HGFs. Fig. 1B shows that a sole stimulation of TNF- $\alpha$ could induce CCL11 production in HGFs. IL-4 also greatly increased CCL11 production in TNF- $\alpha$-treated HGFs like IL-1 $\beta$.

\section{Effects of EGCG on CCL11 production in HGFS}

We next investigated the effects of EGCG on CCL11 production in IL-1 $\beta+$ IL- 4 or TNF$\alpha+$ IL-4-stimulated HGFs because combinations of IL-1 $\beta /$ IL- 4 or TNF- $\alpha /$ IL- 4 induced a large amount of CCL11 production in HGFs. Fig. 2A and B demonstrate that EGCG inhibited CCL11 productions in HGFs in a dose-dependent fashion.

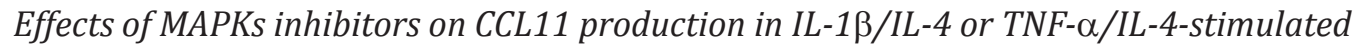
HGFS

A previous report demonstrated that MAPKs were involved in CCL11 productions in thymic stromal lymphopoietin (TSLP)-stimulated human airway smooth muscle cells [18]. 

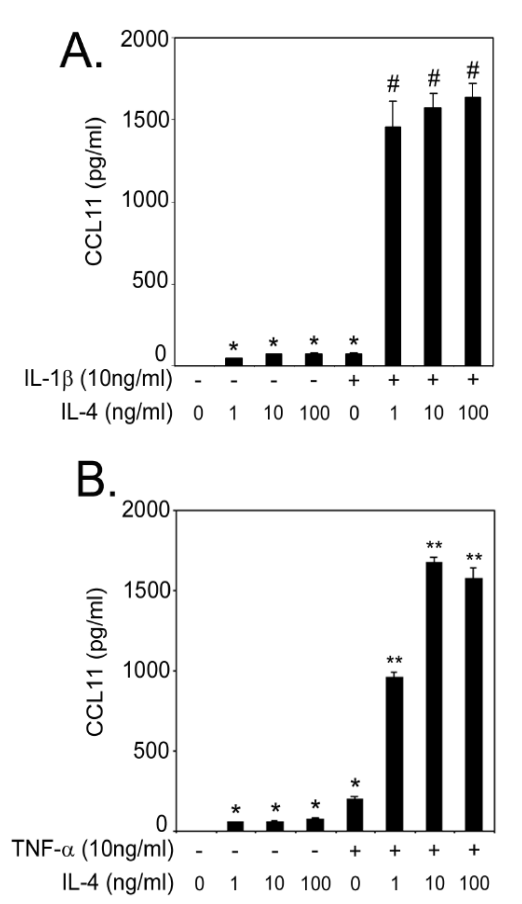

Fig. 1. Effects of IL- $1 \beta$, TNF- $\alpha$, or IL-4 stimulation on CCL20 production in HGFs. (A) HGFs were activated for 24 hours with IL-1 $\beta$, IL-4 or mixtures of both cytokines at designated concentrations. The expression levels of CCL11 in the supernatants were measured using ELISA. Data are representative of three different HGFs samples from three different donors. The results are shown as the mean and SD of one representative experiment performed in triplicate. The error bars show the SD of the values. ${ }^{*}=$ $\mathrm{P}<0.05$; significantly different from the non-stimulated HGFs. $\#=\mathrm{P}<0.05$; significantly different from the IL-1 $\beta$-stimulated HGFs. (B) HGFs were activated for 24 hours with TNF- $\alpha$, IL-4 or mixtures of both cytokines at designated concentrations. The expression levels of CCL11 in the supernatants were measured using ELISA. Data are representative of three different HGFs samples from three different donors. The results are shown as the mean and SD of one representative experiment performed in triplicate. The error bars show the SD of the values. ${ }^{*}=$ $\mathrm{P}<0.05$; significantly different from the non-stimulated HGFs. ${ }^{* *}=\mathrm{P}<0.05$; significantly different from the TNF- $\alpha$-stimulated HGFs.

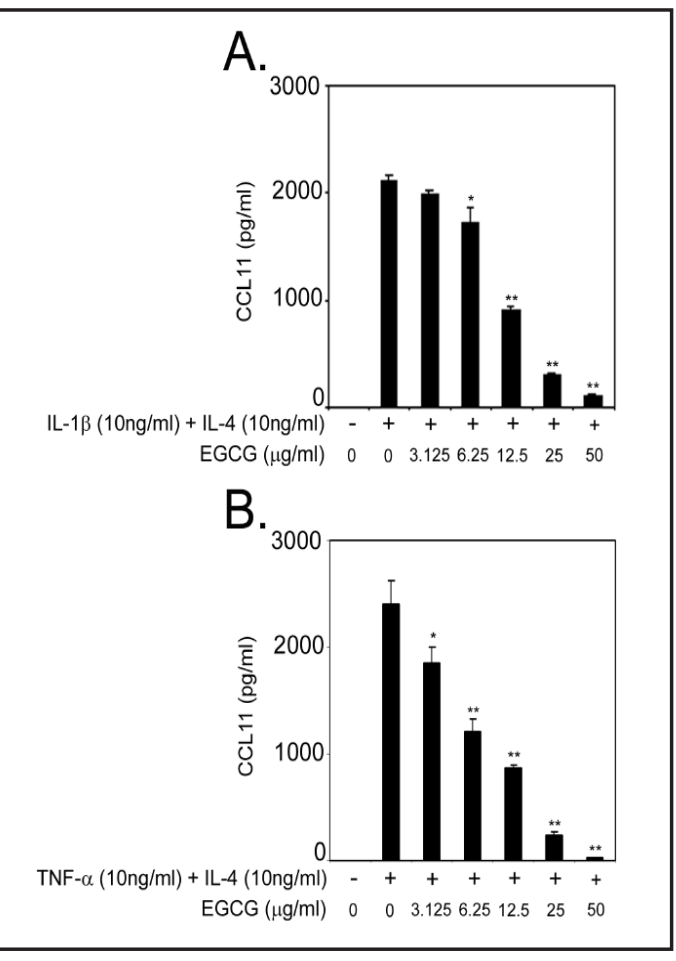

Fig. 2. Effects of EGCG on CCL11 production in IL$1 \beta /$ IL- 4 or TNF- $\alpha /$ IL-4-stimulated HGFs. (A) HGFs were pretreated with EGCG $(3.125,6.25,12.5$, 25, or $50 \mu \mathrm{g} / \mathrm{ml}$ ) for 1 hour, and then the HGFs were stimulated with IL-1 $\beta(10 \mathrm{ng} / \mathrm{ml})$ and IL-4 $(10 \mathrm{ng} / \mathrm{ml})$, and the supernatants were collected after 24 hours. The expression levels of CCL11 in the supernatants were measured using ELISA. Data are representative of three different HGFs samples from three different donors. Data indicate the mean \pm SD of three cultures. The error bars show the SD of the values. ${ }^{*}=$ $\mathrm{P}<0.05,{ }^{* *}=\mathrm{P}<0.01$; significantly different from the IL-1 $\beta /$ IL-4-stimulated HGFs without EGCG. (B) HGFs were pretreated with EGCG $(3.125,6.25,12.5$, 25, or $50 \mu \mathrm{g} / \mathrm{ml}$ ) for 1 hour, and then the HGFs were stimulated with TNF- $\alpha(10 \mathrm{ng} / \mathrm{ml})$ and IL-4 $(10 \mathrm{ng} / \mathrm{ml})$, and the supernatants were collected after 24 hours. The expression levels of CCL11 in the supernatants were measured using ELISA. Data are representative of three different HGFs samples from three different donors. Data indicate the mean \pm SD of three cultures. The error bars show the SD of the values. ${ }^{*}=$ $\mathrm{P}<0.05, * *=\mathrm{P}<0.01$; significantly different from the TNF- $\alpha$ /IL-4-stimulated HGFs without EGCG.

Therefore, we examined the effects of MAPKs inhibitors on CCL11 production in HGFs to reveal the role of MAPKs. Fig. 3A and B shows that SB203580 (a p38 MAPK inhibitor), PD98059 (an ERK inhibitor), and SP600125 (a JNK inhibitor) significantly decreased CCL11 productions from IL- $1 \beta / \mathrm{IL}-4$ or TNF- $\alpha /$ IL- 4 -stimulated HGFs. These results apparently show that p38 MAPK, ERK, and JNK pathways positively control CCL11 production from HGFs stimulated with IL-1 $\beta /$ IL-4 or TNF- $\alpha /$ IL-4. 
Fig. 3. Effects of signal transduction inhibitors on IL$1 \beta /$ IL- 4 or TNF- $\alpha /$ IL-4-stimulated CCL11 release by HGFs. (A) HGFs were pre-incubated with SB203580 $(20 \mu \mathrm{M})$, PD98059 $(20 \mu \mathrm{M})$, or SP600125 $(20 \mu \mathrm{M})$ for 1 hour and then incubated with IL-1 $\beta(10 \mathrm{ng} / \mathrm{ml})$ with IL-4 (10 ng/ml). After 24 hours incubation, the supernatants were collected, and CCL11 production was measured by ELISA. Data are representative of HGFs from three different donors. Data indicate the mean \pm SD of three cultures. The error bars show the SD of the values. ${ }^{*}=\mathrm{P}<0.05$, significantly different from the IL-1 $\beta /$ IL-4-stimulated HGFs without inhibitors. (B) HGFs were pre-incubated with SB203580 $(20 \mu \mathrm{M})$, PD98059 $(20 \mu \mathrm{M})$, or SP600125 $(20 \mu \mathrm{M})$ for 1 hour and then incubated with TNF- $\alpha$ (10 ng/ $\mathrm{ml})$ with IL-4 (10 ng/ml). After 24 hours incubation, the supernatants were collected, and CCL11 production was measured by ELISA. Data are representative of HGFs from three different donors. Data indicate the mean \pm SD of three cultures. The error bars show the SD of the values. ${ }^{*}=\mathrm{P}<0.05$, significantly different from the TNF- $\alpha /$ IL-4-stimulated HGFs without inhibitors.

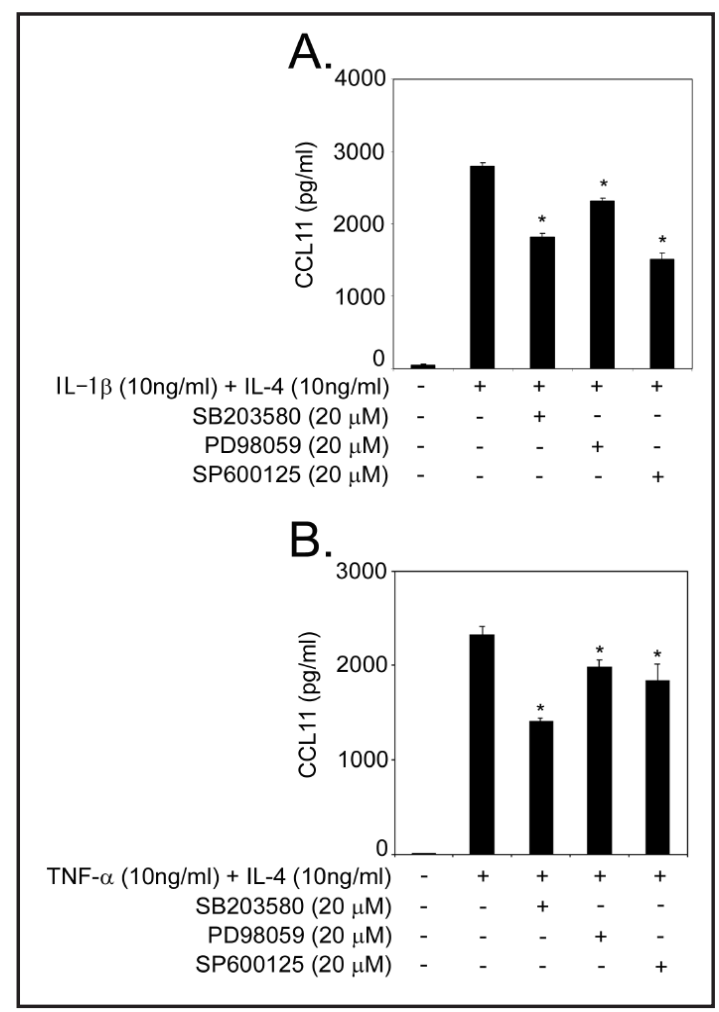

Fig. 4. Effects of EGCG on the IL$1 \beta /$ IL-4-induced phosphorylations of MAPKs. The cultured cells were pretreated with EGCG $(25 \mu \mathrm{g} / \mathrm{ml})$ for $60 \mathrm{~min}$ and then stimulated with IL-1 $\beta(10 \mathrm{ng} / \mathrm{ml})$ and IL-4 (10 $\mathrm{ng} / \mathrm{ml}$ ) for 15,30 , or $60 \mathrm{~min}$. The cell extracts were subjected to SDSPAGE followed by Western blotting analysis with antibodies against phospho-specific p38 MAPK, p38 MAPK, phospho-specific ERK, ERK, phosphor-specific JNK, JNK, and actin levels in HGFs from three different experiments from three different donors.

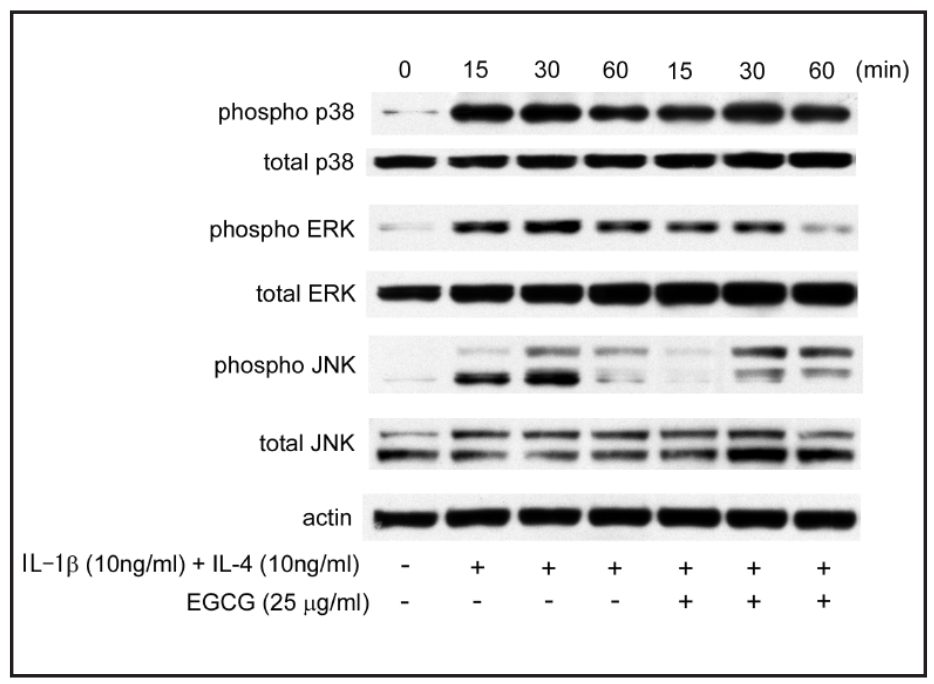

Effects of EGCG on MAPKs pathways in IL-1 /IL-4 or TNF- $\alpha / I L-4$-stimulated HGFs

Fig. 3 shows that MAPKs are related to CCL11 production in HGFs. Therefore, we examined the effect of EGCG on MAPKs activations in IL-1 $\beta /$ IL-4 (Fig. 4) or TNF- $\alpha /$ IL-4 (Fig. 5)-stimulated HGFs. Fig. 4 and Fig. 5 shows that EGCG treatment apparently inhibited ERK phospholyration in IL-1 $\beta / \mathrm{IL}-4$ or TNF- $\alpha / \mathrm{IL}-4$-stimulated HGFs (15min, $30 \mathrm{~min}$, and $60 \mathrm{~min}$ ). EGCG inhibited JNK1 (46 kDa) phospholyration though JNK2 (54 kDa) phospholyration did not change (Fig. 4 and Fig. 5). P38 MAPK phospholyration in IL-1 $\beta /$ IL-4 or TNF- $\alpha /$ IL-4stimulated HGFs did not modify by EGCG treatment. Fig. 4 and Fig. 5 obviously demonstrate that the effects of EGCG on ERK and JNK pathways are involved in the inhibition of CCL11 production from EGCG-treated HGFs. 
Fig. 5. Effects of EGCG on the TNF- $\alpha$ / IL-4-induced phosphorylations of MAPKs. The cultured cells were pretreated with EGCG $(25 \mu \mathrm{g} / \mathrm{ml})$ for $60 \mathrm{~min}$ and then stimulated with TNF- $\alpha$ (10 ng/ml) and IL-4 (10 $\mathrm{ng} / \mathrm{ml}$ ) for 15,30 , or $60 \mathrm{~min}$. The cell extracts were subjected to SDS-PAGE followed by Western blotting analysis with antibodies against phospho-specific p38 MAPK, p38 MAPK, phospho-specific ERK, ERK, phosphor-specific JNK, JNK, and actin levels in HGFs from three different experiments from three different donors.

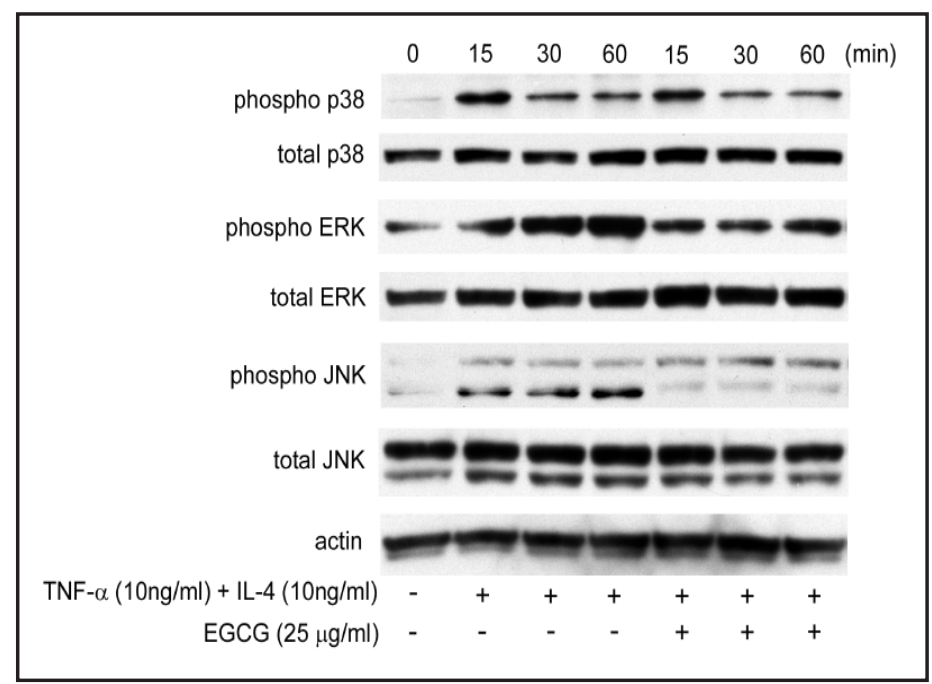

\section{Discussion}

In this study, we demonstrated that HGFs could produce CCL11 which is associated with Th2 cells migration. A previous report revealed that IL-4 stimulation synergistically induced CCL11 production from IL-1 $\beta$-stimulated human airway muscle cells [19]. Kumagai and the colleagues. also reported that stimulation of human keratinocytes with the combination of TNF- $\alpha$ and IL-4 resulted in synergistic increases in the release of CCL11 protein [20]. Their reports and our report show that the combination of IL-1 $\beta$ and IL- 4 or TNF- $\alpha$ and IL-4 enhanced CCL11 productions in some types of cells and, the phenomenon is apparently related to Th2 cells accumulation in inflammatory lesions and the etiology of Th2 type diseases. Moreover, we previously reported that the combination of TNF- $\alpha$ and IL-4 induced CCL17, which is also involved in Th2 cells migration, production in HGFs [21]. Therefore, TNF- $\alpha$ and IL-4 is greatly associated with Th2 cells infiltration in periodontal lesions to induce CCL11 and CCL17 productions.

We demonstrated that EGCG could inhibit CCL11 production in HGFs. This is the first report that tea catechins could modify CCL11 production in any types of cells. However, previous reports explain that catechin treatment could improve the condition of some Th2-type diseases. For example, Kim and the colleagues reported that EGCG treatment protects toluene diisocyanate-induced airway inflammation in a murine model of asthma by supressing matrix metalloproteinase (MMP-9) expression in toluene diisocyanate-inhalation lung tissues as well as TNF- $\alpha$ and Th2 cytokine (IL-5) production in bronchoalveolar lavage fluid [22]. Moreover, Noh and the colleagues demonstrated that EGCG treatment improved Dermatophagoides pteronissinus extract-induced atopic dermatitis-like skin lesions in NC/ Nga mice by suppressing macrophage migration inhibitory factor [23]. These studies did not examine CCL11 production in inflammatory lesions though CCL11 is related to the etiology of asthma and atopic dermatitis. Our study suggests the possibility that EGCG treatment could reduce the expression of CCL11 in asthma and atopic dermatitis lesions and the CCL11 inhibition might be involved in improvement of these diseases conditions. Further investigation should be necessary to verify this possibility.

There are few reports that explain the roles of MAPKs on CCL11 production. In this report, we demonstrated that p38 MAPK, ERK, and JNK pathways are related to CCL11 production in HGFs. Shan and the colleagues previously reported that thymic stromallymphopoietin receptor-mediated CCL11 expression in human airway smooth muscle cells were positively regulated p38 MAPK, ERK, and JNK pathways [18]. The report is the same as results of our report. 
Some researchers examined the effects of EGCG on MAPKs activation. Yun and the colleagues reported that EGCG suppressed TNF- $\alpha$-induced MMP-1 and MMP-3 productions in synovial fibroblasts to inhibit the activations of p38 MAPKs, ERK, and JNK [24]. Hayashi and the colleagues reported that EGCG treatment inhibited JNK phosphorylation in TGF- $\beta 1$-treated osteoblasts though EGCG treatment did not change p38 MAPK and ERK phosphorylation [25]. Our study demonstrated that ERK and JNK activations in HGFs are inhibited by EGCG treatment though EGCG did not change p38 MAPK phosphorylation in HGFs. Discrepancies among these reports might be dependent on the types of cells, the sources of stimulations, and EGCG concentrations.

It is reported that hydrogen peroxide were formed after the addition of EGCG to DMEM [26]. Moreover, Song and the colleagues reported that hydrogen peroxide could induce ERK and JNK activation and did not modulate p38 MAPK activation in smooth muscle cells [27]. The effect of hydrogen peroxide might modulate MAPKs activation in this experiment. Further investigation should be necessary to address this question.

Yang and the colleagues reported that peak saliva levels of EGCG were $4.8-22 \mu \mathrm{g} / \mathrm{ml}$ after drinking green tea preparations equivalent to two to three cups of tea [28]. In this experiment, $6.25 \mu \mathrm{g} / \mathrm{ml}$ of EGCG significantly inhibited CCL11 production in HGFs, and 25 $\mu \mathrm{g} / \mathrm{ml}$ of EGCG apparently suppressed ERK and JNK activation in IL-1 $\beta /$ IL-4 or TNF- $\alpha /$ IL-4stimulated HGFs. We could detect the same concentrations of EGCG in saliva after drinking green tea. Therefore, drinking green tea could decrease CCL11 production in vivo situation.

In summary, the current study demonstrates that HGFs could produce CCL11 by IL$1 \beta$, TNF- $\alpha$, or IL-4 stimulations. Therefore, HGFs could control Th2 cells migration in periodontal lesions. Moreover, EGCG cold inhibit CCL11 production. It is known that Th2 cells are involved in the exacerbation of periodontal disease. Therefore, these data show that we could use EGCG for periodontal disease treatment to decrease CCL11 production in the lesion of periodontal tissues.

\section{Acknowledgements}

This study was supported by Grant-in-Aid for Young Scientists (21792123) from the Ministry of Education, Culture, Sports, Science and Technology of Japan.

\section{References}

$>1$ Taubman MA, Yoshie H, Ebersole JL, Smith DJ, Olson CL: Host response in experimental periodontal disease. J Dent Res 1984;63:455-460.

2 KatzJ, Black KP, Michalek SM: Host responses to recombinant hemagglutinin B of Porphyromonas gingivalis in an experimental rat model. Infect Immun 1999;67:4352-4359.

- Yamazaki K, Nakajima T, Hara K: Immunohistological analysis of T cell functional subsets in chronic inflammatory periodontal disease. Clin Exp Immunol 1995;99:384-391.

-4 Afar B, Engel D, Clark EA: Activated lymphocyte subsets in adult periodontitis. J Periodontal Res 1992;27:126-133.

-5 Myneni SR, Settem RP, Connell TD, Keegan AD, Gaffen SL, Sharma A: TLR2 signaling and Th2 responses drive Tannerella forsythia-induced periodontal bone loss. J Immunol 2011;187:501-509.

6 Rothenberg ME: Eotaxin: An essential mediator of eosinophil trafficking into mucosal tissues. Am J Respir Cell Mol Biol1999;21:291-295.

7 Menzies-Gow A, Ying S, Sabroe I, Stubbs VL, Soler D, Williams TJ, Kay AB: Eotaxin (CCL11) and eotaxin-2 (CCL24) induce recruitment of eosinophils, basophils, neutrophils, and macrophages as well as features of early- and late-phase allergic reactions following cutaneous injection in human atopic and nonatopic volunteers. J Immunol 2002;169:2712-2718.

8 Miyagaki T, Sugaya M, Fujita H, Ohmatsu H, Kakinuma T, Kadono T, Tamaki K, Sato S: Eotaxins and CCR3 interaction regulates the Th2 environment of cutaneous T-cell lymphoma. J Invest Dermatol 2010;130:23042311. 
9 Webb DC, McKenzie AN, Matthaei KI, Rothenberg ME, Foster PS: Distinct spatial requirement for eosinophil-induced airways hyperreactivity. Immunol Cell Biol 2001;79:165-169.

10 Minshall EM, Cameron L, Lavigne F, Leung DY, Hamilos D, Garcia-Zepada EA, Rothenberg M, Luster AD, Hamid Q: Eotaxin mRNA and protein expression in chronic sinusitis and allergen-induced nasal responses in seasonal allergic rhinitis. Am J Respir Cell Mol Biol 1997;17:683-690.

11 Owczarek W, Paplińska M, Targowski T, Jahnz-Rózyk K, Paluchowska E, Kucharczyk A, Kasztalewicz B: Analysis of eotaxin 1/CCL11, eotaxin 2/CCL24 and eotaxin 3/CCL26 expression in lesional and non-lesional skin of patients with atopic dermatitis. Cytokine 2010;50:181-185.

12 Thunell DH, Tymkiw KD, Johnson GK, Joly S, Burnell KK, Cavanaugh JE, Brogden KA, Guthmiller JM: A multiplex immunoassay demonstrates reductions in gingival crevicular fluid cytokines following initial periodontal therapy. J Periodontal Res 2010;45:148-152.

13 Weisburger JH: Tea and health: the underlying mechanisms. Proc Soc Exp Biol Med 1999;220:271-275.

14 Chen D, Milacic V, Chen MS, Wan SB, Lam WH, Huo C, Landis-Piwowar KR, Cui QC, Wali A, Chan TH, Dou QP: Tea polyphenols, their biological effects and potential molecular targets. Histol Histopathol 2008;23:487496.

15 Hosokawa Y, Hosokawa I, Ozaki K, Nakanishi T, Nakae H, Matsuo T: Tea polyphenols inhibit IL-6 production in tumor necrosis factor superfamily 14-stimulated human gingival fibroblasts. Mol Nutr Food Res 2010;54:S151-158.

16 Hosokawa Y, Hosokawa I, Ozaki K, Nakanishi T, Nakae H, Matsuo T: Catechins inhibit CCL20 production in IL-17A-stimulated human gingival fibroblasts. Cell Physiol Biochem 2009;24:391-396.

17 Hosokawa Y, Hosokawa I, Ozaki K, Nakanishi T, Nakae H, Matsuo T: Catechins inhibit CXCL10 production from oncostatin M-stimulated human gingival fibroblasts. J Nutr Biochem 2010;21:659-664.

18 Shan L, Redhu NS, Saleh A, Halayko AJ, Chakir J, Gounni AS: Thymic stromal lymphopoietin receptormediated IL-6 and CC/CXC chemokines expression in human airway smooth muscle cells: role of MAPKs (ERK1/2, p38, and JNK) and STAT3 pathways. J Immunol 2010;184:7134-7143.

19 Hirst SJ, Hallsworth MP, Peng Q, Lee TH: Selective induction of eotaxin release by interleukin-13 or interleukin-4 in human airway smooth muscle cells is synergistic with interleukin-1beta and is mediated by the interleukin-4 receptor alpha-chain. Am J Respir Crit Care Med 2002;165:1161-1171.

20 Kumagai N, Fukuda K, Ishimura Y, Nishida T: Synergistic induction of eotaxin expression in human keratocytes by TNF-alpha and IL-4 or IL-13. Invest Ophthalmol Vis Sci 2000;41:1448-1453.

-21 Hosokawa Y, Hosokawa I, Ozaki K, Nakae H, Matsuo T: CC chemokine ligand 17 in periodontal diseases: expression in diseased tissues and production by human gingival fibroblasts. J Periodontal Res 2008;43:471477.

-22 Kim SH, Park HJ, Lee CM, Choi IW, Moon DO, Roh HJ, Lee HK, Park YM: Epigallocatechin-3-gallate protects toluene diisocyanate-induced airway inflammation in a murine model of asthma. FEBS Lett 2006;580:1883-1890.

-23 Noh SU, Cho EA, Kim HO, Park YM: Epigallocatechin-3-gallate improves Dermatophagoides pteronissinus extract-induced atopic dermatitis-like skin lesions in NC/Nga mice by suppressing macrophage migration inhibitory factor. Int Immunopharmacol 2008;8:1172-1182.

-24 Yun HJ, Yoo WH, Han MK, Lee YR, Kim JS, Lee SI: Epigallocatechin-3-gallate suppresses TNF-alpha -induced production of MMP-1 and -3 in rheumatoid arthritis synovial fibroblasts. Rheumatol Int 2008;29:23-29.

25 Hayashi K, Takai S, Matsushima-Nishiwaki R, Hanai Y, Kato K, Tokuda H, Kozawa O: (-)-Epigallocatechin gallate reduces transforming growth factor beta-stimulated HSP27 induction through the suppression of stress-activated protein kinase/c-Jun N-terminal kinase in osteoblasts. Life Sci 2008;82:1012-1017.

26 Long LH, Clement MV, Halliwell B: Artifacts in cell culture: rapid generation of hydrogen peroxide on addition of (-)-epigallocatechin, (-)-epigallocatechin gallate, (+)-catechin, and quercetin to commonly used cell culture media. Biochem Biophys Res Commun 2000;273:50-53.

27 Song HJ, Lee TS, Jeong JH, Min YS, Shin CY, Sohn UD: Hydrogen peroxide-induced extracellular signal-regulated kinase activation in cultured feline ileal smooth muscle cells. J Pharmacol Exp Ther 2005;312:391398.

28 Yang CS, Lee MJ, Chen L: Human salivary tea catechin levels and catechin esterase activities: implication in human cancer prmarker Prev 1999;8:83-89. 